\title{
MAIS GRAVE! COMO AS TECNOLOGIAS MIDIÁTICAS AFETAM AS SENSORIALIDADES AUDITIVAS E OS CÓDIGOS SONOROS CONTEMPORÂNEOS ${ }^{1}$ \\ Vinícius Andrade Pereira ${ }^{2}$ \\ José Cláudio Castanheira ${ }^{3}$
}

\begin{abstract}
Resumo: $O$ artigo investiga a emergência de novas sensorialidades auditivas, mais especificamente um modelo de audibilidade tátil-acústica, relativas às práticas de comunicação das últimas décadas. Consideramos que os sons extremos - graves e potentes - e a maneira como eles se inserem em linguagens como a música, o cinema e os games podem ser indícios de novas demandas sensoriais capazes de alterar os códigos sonoros vigentes nas mídias digitais.
\end{abstract}

Palavras-chave: Sensorialidades. Audibilidades. Sons extremos.

\begin{abstract}
This article investigates the emerging of new audible sensorialities, more specifically, a model of tactile-acoustic audibility, related to communication practices over the last decades. We consider that extreme sounds - low pitched and potent - and the way they are inserted in languages such as music, cinema and games may be indications of new sensorial demands capable of altering the current sound codes in digital media.
\end{abstract}

Key words: Sensorialities. Audibilities. Extreme sounds.

Tá faltando grave! Eu quero mais grave! Tim Maia

\section{Introdução}

Sons, imagens, texturas, olfatos e sabores são conjuntos de estímulos e de sensações específicos de cada época e cultura. Como também as experiências sensoriais e suas valorações. O mundo contemporâneo nos oferece um conjunto de experiências sensoriais típicas, jamais vividas e certamente ainda não valoradas de modo claro - a capacidade de composição e audição de sons sintéticos, sem relação direta com instrumentos musicais tradicionais ou mecanismos não eletrônicos, através da manipulação de códigos numéricos e de ferramentas como os computadores; a produção e visualização de holografias e de imagens

\footnotetext{
${ }^{1}$ Convidamos a todos interessados no tema tratado por este artigo a visitarem a versão multimídia deste texto, no seguinte endereço: <http://maisgrave.blogspot.com>.

${ }^{2}$ Professor e diretor do PAN MEDIA LAB da ESPM e do Programa de Pós-Graduação em Comunicação da UERJ. Sócio fundador e atual diretor científico da ABCiber - Associação Brasileira dos Pesquisadores em Cibercultura. Pesquisador associado do McLuhan Program in Culture and Technology, da Universidade de Toronto, Canadá. Email: vinianp10@gmail.com.

${ }^{3}$ Doutorando em Comunicação pela Universidade Federal Fluminense - UFF. Mestre em Comunicação pela Universidade do Estado do Rio de Janeiro - UERJ. Professor da Universidade Federal de Santa Catarina UFSC. E-mail: jcscastanheira@gmail.com
} 
digitais; o imenso conjunto de tecnologias que são operadas a partir de interfaces sensíveis ao toque (touch screen), redefinindo as ideias sobre arquitetura da informação, até então baseada exclusivamente na visualidade. São todos acontecimentos e experiências sensoriais novas, que participam diretamente das experiências de comunicação mediada tecnologicamente, possíveis graças à entrada das mídias digitais na cultura contemporânea ${ }^{4}$. Contudo, boa parte de todo este novo conjunto de experiências que emergem ainda é desconhecida nos modos como afeta e participa das práticas comunicacionais e culturais contemporâneas.

Apostamos, em outro momento, que a história das culturas pode ser escrita, dentre tantas outras perspectivas, comparando-se os conjuntos tecnológicos e os correlatos padrões sensoriais emergentes em cada época (PEREIRA, 2008). Ou seja, observando e comparando as sensorialidades ${ }^{5}$ cultivadas por uma dada sociedade quando esta introduz novos artefatos tecnológicos nas suas dinâmicas cotidianas, artefatos que, por sua vez, são marcados por sensorialidades prévias. Esta perspectiva, se levada a cabo na contemporaneidade implicando a possibilidade da construção de uma espécie de radar das sensorialidades em processo - deverá, necessariamente, passar pela análise das relações entre os padrões sensoriais e suas afetações a partir do contato permanente com as tecnologias digitais que caracterizam as culturas metropolitanas de hoje.

Entendendo como superada a velha questão do determinismo tecnológico ${ }^{6}$, a proposição que apresentamos é a de que novos conjuntos tecnológicos, quando inseridos como parte das práticas culturais de uma dada sociedade, estimulam alterações sensoriais mais profundas, que se inscrevem corporalmente, a partir da plasticidade cerebral que, neste caso, deve ser entendida como a capacidade de todo o corpo se reorganizar e atuar sensorialmente.

A hipótese que aventamos é a de que a cultura contemporânea - sempre pensada a partir das suas mediações tecnológicas - estimula modelos de audibilidades que requerem, cada vez mais, sons intensos, valorizando, consequentemente, sons graves, sons que exigem e emanam mais energia física para a sua efetivação como experiência acústica. Por outro lado, exatamente por conta dessa intensidade com que os sons graves se apresentam, as

\footnotetext{
${ }^{4}$ Inspirados em Gumbrecht (1995;2004), tomaremos o termo experiência como o conjunto de processos, não necessariamente hermenêuticos, de observação pelos sentidos e de apropriação através de conceitos. Vale lembrar, ainda, uma ideia afim proposta por John Dewey (1929) a respeito da experiência, tomando-a não como um registro passivo de estímulos externos, mas como um efeito conjunto das ações recíprocas do organismo e do ambiente.

${ }_{5}^{5}$ Para as ideias de corpo e de sensorialidades tratadas neste texto, ver Reflexões sobre as materialidades dos meios: embodiment, afetividade e sensorialidade nas dinâmicas de comunicação das novas mídias (Cf. Pereira, 2006b).

${ }^{6}$ Para uma reflexão sobre o tema do determinismo tecnológico e suas relações com as tecnologias de comunicação, ver Marshall McLuhan, o conceito de determinismo tecnológico e os estudos dos meios de comunicação contemporâneos (Cf. Pereira, 2006a).
} 
audibilidades contemporâneas são elaboradas de modo cada vez mais explícito como audibilidades táteis-acústicas, entendendo com isso a ideia de que, em meio às práticas típicas dos G.A.M.E.S.2.0. ${ }^{7}$, escutamos cada vez mais com todo o corpo e menos especificamente com os ouvidos. Que consequências isso pode trazer para os códigos que se estabelecem a partir de sons nas culturas hodiernas? Ou, como se estabelecem os códigos sonoros que participam dos arranjos e ambientes midiáticos (PEREIRA, 2008), ante um modelo de audibilidade que demanda sons intensos? Estas são algumas das questões que queremos encaminhar.

\section{O som grave}

Por volta de 250 A.C., Ktesibios de Alexandria, inventor e matemático grego, escrevia os primeiros tratados sobre a compressão do ar. Ao desenvolver um mecanismo que permitia, através da pressão da água, empurrar uma coluna de ar para dentro de tubos, Ktesibios criou o Hydraulos. Esse instrumento era constituído de sete tubos de diferentes tamanhos e um teclado rudimentar. A pressão hidráulica foi substituída entre os séculos VI e VII por foles de ar que forneciam energia suficiente para o funcionamento do instrumento. O órgão instalado na cidade alemã de Halberstadt, em 1361, possuía vinte foles que eram operados por dez homens. "Quando a pressão do ar estava forte, o músico tinha que usar toda a força de seu braço para segurar uma tecla" (KENNEDY, 2002: 644).

A utilização de mecanismos pneumáticos acionados por motores elétricos facilitou muito a vida dos foleiros e, ao mesmo tempo, atendeu à crescente necessidade, durante o século XIX, de um som mais potente. Essa potência foi especialmente bem-vinda no caso das notas mais graves: é só lembrarmos que alguns dos maiores órgãos construídos possuem tubos de até 64 pés (mais ou menos 19,5 metros) e que são capazes de produzir uma nota fundamental de $8.18 \mathrm{~Hz}$ (Dó -1). Uma onda sonora desse comprimento, apesar de necessitar de uma considerável energia para vibrar e se deslocar, não é sequer percebida pelo nosso ouvido. A sensação que temos de uma nota tão grave é dada pelos harmônicos - vibrações secundárias de um som fundamental - mais próximos de nossa faixa de frequências audíveis (aproximadamente de $20 \mathrm{~Hz}$ a $20 \mathrm{kHz}$ ). As ondas de baixa frequência necessitam de espaço para se propagarem. Perto dos tubos elas são praticamente inaudíveis. Frequências abaixo dos $20 \mathrm{~Hz}$ anunciam a sua presença pelo impacto físico, por sua ação sobre nossa pele, músculos,

\footnotetext{
${ }^{7}$ G.A.M.E.S.2.0. - Gêneros e Gramáticas de Arranjos e Ambientes Midiáticos Moduladores de Experiências de Entretenimento, Sociabilidades e Sensorialidades (Cf. Pereira, 2008).
} 
vísceras e ossos. Como uma experiência tátil ainda que, também, acústica. O corpo humano funciona, assim, como uma caixa de ressonância e a experiência de escuta deixa de privilegiar apenas um dos sentidos.

O grande órgão é, antes de qualquer coisa, um projeto grandioso de ampliar os limites da nossa percepção auditiva. Tanto para um extremo, de sons subgraves, inaudíveis em pequenos espaços, quanto para o outro, das notas muito agudas, o órgão tenta dar conta de todas as possibilidades de um projeto acústico herdado de períodos anteriores e que, de alguma forma, pode ser compreendido através das audibilidades que vinham sendo cultivadas nesses períodos através da escuta de variados tipos de sons - musicais ou não -, ainda que menores e menos potentes ${ }^{8}$.

\section{O projeto tecnocientífico e as tecnologias sonoras}

A Segunda Grande Guerra foi responsável pelo surgimento de novas tecnologias em diversas áreas. Mais do que isso, foi responsável pela disseminação da ideia de que, para o bem e para o mal, a cultura tecnocientífica estava inexoravelmente determinando nossas vidas. As bombas lançadas em Hiroshima e Nagasaki fizeram surgir sentimentos contraditórios no mundo a respeito dos males e dos possíveis benefícios do desenvolvimento tecnológico. O Projeto Manhattan, nome dado ao programa nuclear norte-americano durante a Guerra, tornou-se uma das maiores proezas da ciência de todos os tempos. Segundo Timothy Taylor foi esse imaginário tecnológico que ganhou a guerra, afinal "se a bomba era vista ou não como uma invenção benéfica ou problemática, o papel cada vez mais evidente que a ciência e a tecnologia exerciam nas vidas das pessoas comuns, após a guerra, era indiscutível" (TAYLOR, 2001: 42).

O governo norte-americano empreendeu uma grande campanha para tentar tornar bem aceito pela sociedade civil o esforço tecnocientífico do Estado, principalmente no que dizia respeito ao desenvolvimento da tecnologia nuclear.

Os aparelhos "hi-fi" (high fidelity) encarnavam boa parte do desejo (um desejo masculino, segundo Taylor) pela perfeição técnica e avanços científicos da época, aplicados ao universo sonoro. Alguns do LPs lançados nesse período tomam como motivo os avanços tecnológicos, especialmente o programa espacial. Assim temos: "Music out of the moon"

\footnotetext{
${ }^{8}$ Para Murray Schafer (2001) o grande órgão pode ser encarado como uma continuação na linhagem dos "ruídos sagrados": aqueles que poderiam, através de sua força, impactar o ouvinte, causando emoções como medo, encanto, euforia, respeito, etc. O divino era representado também pelos sinos, com sons que poderiam competir com aqueles dos grandes eventos naturais - como o trovão - ou com aqueles produzidos pelo homem - como o canhão. $\mathrm{O}$ órgão, reverberando no interior das igrejas, era utilizado para fazer a divindade ouvir.
} 
(1947), "Other worlds, other sounds" (1958), "Music for heavenly bodies" (1959), "Strings for a space age” (1959), entre outros. Todos, quase sem exceção, traziam na capa um cenário de outro planeta, um foguete ou nave espacial e uma mulher em trajes sumários. É importante salientar que o imaginário em questão destaca-se mais pela aposta na alta tecnologia do que na questão da energia nuclear especificamente. Ou seja, esta seria apenas uma das faces do inevitável - e vendido como altamente promissor - desenvolvimento tecnocientífico. Este fenômeno não ocorreu apenas nos Estados Unidos. Outros países, como a França, logo demonstraram interesses parecidos. "O desenvolvimento da bomba atômica pelos Estados Unidos precipitou um movimento renovado para financiar a ciência e a tecnologia e exerceu um papel central na ascensão de uma França moderna e tecnocrática” (TAYLOR, 2001: 43).

Podemos identificar essa ambição tecnocientífica afetando também as práticas sonoras, mais especificamente as musicais, através de dois movimentos surgidos na Europa na década de 50: a musique concrète, que teve como um de seus mentores o compositor francês Pierre Schaeffer (1966), e a elektronische Musik, movimento inaugurado por Herbert Eimert, com seus experimentos na rádio alemã NWDR, em Colônia.

\section{Som, ruído e hiperestímulo}

Os dois movimentos buscavam novas direções na música e, embora notadamente diferentes nas suas propostas conceituais, estavam ambos sob o efeito das imagens encantadoras forjadas pela cultura tecnocientífica. Conceitualmente, poderíamos dizer que enquanto a música concreta buscava uma proximidade do caráter material do som, de como a experiência sonora deve estar liberada de seu caráter metafísico (que buscava um sentido para além de seu aspecto material), a música eletrônica se apegava ao projeto da síntese de ondas senoidais puras, de frequências precisas. Ou seja, o som poderia ser criado por meio de equipamentos eletrônicos, dando ao compositor total controle sobre seus parâmetros.

Schaeffer demonstra interesse, muito em função dos novos mecanismos de registro do som (a gravação em fita magnética, principalmente), pelos elementos descartados na música tradicional. Enquanto a frequência da onda sonora sempre foi (e de certa forma ainda é) o elemento considerado o mais importante na tradição ocidental, o caminho tomado por Schaeffer foi o de vislumbrar e valorizar aqueles sons de maior complexidade espectral e sem uma frequência ou tom dominante. Um caminho já antevisto pelo futurista Luigi Russolo na primeira década do século XX: 
O som da música é muito limitado na variedade qualitativa dos timbres. A orquestra mais complexa se reduz a quatro ou cinco classes de instrumentos, em diferentes timbres de som: instrumentos de arco, beliscados, de sopro de metais, de sopro de madeiras, de percussão. Portanto, a música moderna se debate neste pequeno círculo, tentando em vão criar novas variedades de timbres. É preciso romper este círculo restrito de sons puros e conquistar a variedade infinita dos sons-ruídos. (RUSSOLO, 1916: 11)

Para Russolo, o ruído, por não se prender a um grupo de frequências predominantes e por apresentar uma maior riqueza espectral, seria uma evolução do som musical. Uma matéria rica de significados e em consonância com os novos tempos.

A posição de Russolo reflete, em parte, uma valorização das dinâmicas urbanas das grandes metrópoles do início do século XX, presente tanto nas análises quanto nas obras de alguns pensadores e artistas da época. Mais do que isso, reflete a ideia recorrente entre alguns intelectuais de que as tecnologias modernas preparavam os corpos para respostas que o ambiente cultural demandava, do mesmo modo que, reciprocamente, os corpos afetados pelo conjunto ambiente/tecnologias influenciavam as linguagens das tecnologias midiáticas emergentes.

O hiperestímulo, conceito proposto pelo reformador social Michael Davis, no início do século XX, inspirado por esse novo cenário urbano, deve ser entendido como novas formas pelas quais o corpo ficava exposto a novas modalidades de estimulação e de excitação sensorial, podendo, assim, demandar - em uma espécie de vício - novas sensorialidades para dar conta da própria vida intensa que se apresentava nas grandes metrópoles ${ }^{9}$. Assim, o hiperestímulo - um conjunto de estímulos intensos táteis, visuais e/ou auditivos - passa a ser um ingrediente não apenas das dinâmicas urbanas relacionadas aos meios de transporte (na forma de buzinas, velocidade, choques provocados por colisões, etc.), à construção civil (acidentes de trabalho), às indústrias (apitos das fábricas, poluição auditiva, calor intenso, etc.), à publicidade visual (excesso de mensagens visuais), mas que comparece também junto às práticas sociais e culturais da época, como os espetáculos sensacionalistas, os circos de horrores, às exibições públicas de cadáveres, às exibições de cinema, dentre outras (SINGER, 2004).

Walter Benjamin cotejava perspectiva próxima, que associa as tecnologias de uma época ao cultivo de certas sensorialidades ao tratar, dentre outros temas, das cidades modernas e das suas relações com o cinema. Este era apontado por Benjamin como uma maneira de

\footnotetext{
${ }^{9}$ Simmel identifica, a partir do século XVIII, na base psicológica do tipo de individualidade metropolitana, uma "intensificação dos estímulos nervosos, que resulta da alteração brusca e ininterrupta entre estímulos exteriores e interiores" (SIMMEL, 1987: 12).
} 
conformar os sentidos do homem metropolitano moderno à nova realidade industrial e urbana, do mesmo modo que o cinema só poderia gerar uma experiência estética para os homens já marcados pelos excessos hiperestimulantes das grandes cidades.

Benjamin chama de "segunda natureza" a forma como a técnica emancipada se confronta com a sociedade moderna:

Diante dessa segunda natureza, que o homem inventou mas há muito não controla, somos obrigados a aprender, como outrora diante da primeira. Mais uma vez, a arte põe-se a serviço desse aprendizado. Isso se aplica, em primeira instância, ao cinema. O filme serve para exercitar o homem nas novas percepções e reações exigidas por um aparelho técnico cujo papel cresce cada vez mais em sua vida cotidiana. Fazer do aparelho técnico do nosso tempo o objeto das inervações humanas - é essa a tarefa histórica cuja realização dá ao cinema o seu verdadeiro sentido. (BENJAMIN, 1994: 174)

Compositores como Edgard Varèse, já na década de 30, incluíam elementos da paisagem sonora urbana em suas peças, misturando-os com instrumentos tradicionais. Sua famosa peça, Ionisation, conta com treze percussionistas, uma sirene e um lion's roar ${ }^{10}$. O ruído tentava estabelecer-se como elemento musical.

Contudo, ainda que o ruído comece a provocar o cenário musical erudito e dar os seus primeiros passos no campo da música massiva, com as primeiras guitarras e sintetizadores (estes, alguns anos depois) que começam, aos poucos, a habitar o cenário musical do inaugural rock'n roll, o contexto da música experimental nos anos 50 foi também o momento da procura pela precisão sonora. A precisão das frequências, obtidas por osciladores eletrônicos nos processos de síntese foi um dos elementos fundamentais para a ruptura entre a elektronische Musik e a musique concrète. Ao desenvolver e trabalhar com um aparato tecnológico na geração e modificação de sons precisos - basicamente circuitos para gerar ondas senoidais, gravadores e reprodutores de alta fidelidade - os compositores ligados à música eletrônica deixavam claro um método de composição cerebral e lógico. Entretanto, curiosamente, esses mesmos aparatos tecnológicos e todo o conhecimento adquirido pela pesquisa dos parâmetros sonoros acabarão por migrar, alguns anos depois, para as indústrias do cinema e da música, propiciando, depois de algumas décadas de consumo de bens massivos de entretenimento, novas sensorialidades auditivas que reencontram e demandam ruídos intensos e sons furiosos. Ou seja, a tecnologia que permitiu a geração e o controle de sons, inicialmente em busca de pureza da matéria sonora, acabou por ajudar na criação de

\footnotetext{
${ }^{10}$ Instrumento de percussão no formato de um vaso cilíndrico com um de seus lados coberto por uma membrana. Uma corda resinada é passada através de um furo e friccionada com uma luva áspera, produzindo um som que lembra o rugido de um leão. Conhecido na Europa, China e Índia.
} 
sons mais graves e mais potentes e de um novo tipo de escuta, alterando a paisagem sonora, em uma afetação que se traduz pela busca de sons graves, extremos e ruidosos.

\section{Dispositivos táteis-áudio-visuais e a emergência de novas audibilidades}

As tecnologias de reprodução sonora de alta fidelidade vinham se desenvolvendo desde a década de 30 com bastante rapidez, apenas o seu uso é que permaneceu conservador por um bom tempo. Poderíamos dizer que ainda não havia audibilidades suficientemente cultivadas que demandassem intensidade e fidelidade sonora como características da espectorialidade cinematográfica. Aliás, isso parece se manter por um bom tempo se considerarmos que, em relação à sonorização das salas de exibição, não houve grandes investimentos e melhorias sensíveis por um longo período que vai da década de 30 à década de 70 , muito por conta do receio dos exibidores que viam o som apenas como um elemento secundário do cinema. "A faixa de frequências e a qualidade do som na maioria dos cinemas não era muito melhor que aquelas dos telefones e continuou assim até metade dos anos 70, até a chegada do Dolby" (SERGI, 2004: 14).

Ray Dolby desenvolveu, no início da década de 70, um sistema de redução de ruídos e ampliação do espectro sonoro nos filmes. Por não necessitar de grandes investimentos na modificação das salas o sistema obteve um relativo sucesso junto aos exibidores, mas ainda restava um problema: a que tipo de filme esse modelo de som se prestava? Algumas tentativas foram feitas com musicais como Tommy (Ken Russel, 1975) e Nasce uma estrela (A star is born, Frank Pierson, 1976), mas, aparentemente, o potencial da nova tecnologia estava sendo subutilizado.

Foi com Guerra nas estrelas (Star Wars, George Lucas, 1977) que Ray Dolby e a indústria cinematográfica, de um modo geral, perceberam que estavam diante de um novo modelo de exibição. $\mathrm{O}$ formato era perfeito para uma sensibilização das plateias como nunca havia sido feito antes. A espacialização do som (que a bem da verdade já havia sido pensada na década de 50, sem muito sucesso), a potência dos graves, os efeitos especiais, traduzidos em uma coordenação feérica de sons e imagens, foram formas encontradas para uma intensificação dos estímulos sobre o público. A cópia em $70 \mathrm{~mm}$ de Guerra nas estrelas, além das várias pistas de som, possuía um tipo de codificação para dar ênfase a sons subgraves (sons abaixo dos $30 \mathrm{~Hz}$, que possuem um impacto grande sobre o corpo, fazendo-o vibrar), produzindo uma sensação de envolvimento físico do espectador com a narrativa fílmica.

Também na década de 70 encontramos um tipo de experiência que, se não totalmente bem sucedida, é bastante significativa na questão que envolve um novo tipo de resposta 
sensorial frente ao poder dos recursos sonoros. O sistema Sensurround foi desenvolvido pela Universal para o lançamento, em 1974, do filme Terremoto (Earthquake, Mark Robson). O sistema contava com grandes subwoofers Cerwin-Wega, posicionados sob a tela e amplificados com 1.600 Watts de potência. Frequências em torno de $40 \mathrm{~Hz}$ eram reproduzidas com uma pressão sonora de 110-120 dB. Lustres e cadeiras tremiam, literalmente, no cinema. O sistema causou problemas como danos estruturais em edifícios próximos às salas de exibição e há relatos até de ferimentos em espectadores. Uma segunda versão do sistema, o Sensurround II, previa a reprodução de frequências de até $15 \mathrm{~Hz}$. Muitos alto-falantes foram destruídos por não suportar uma pressão sonora tão grande em frequências tão baixas.

Esse tipo de experiência auditiva intensa, que poderia ser chamada de tátil-acústica e que propomos que seja inscrita dentro do que chamamos genericamente de linguagens visuaudiomotoras (PEREIRA, 2008), tornou-se extremamente comum nos filmes de ação norte-americanos nas décadas seguintes e praticamente construiu uma padronização de como deve ser a escuta de um filme do gênero. Uma escuta que se aproximará cada vez mais da ideia de imersão, tal como encontramos atualmente nos games. Na sequência dessa evolução das audibilidades, teremos os home-theaters, relativamente comuns hoje em dia, que surgem como uma experiência auditiva complexa, intensa e envolvente. A distribuição espacial do som, neste caso, é completada pelos graves que têm o papel de afetação tátil. Mesmo a direcionalidade do som, a sua distribuição em diferentes alto-falantes na sala, não consegue superar a presença impactante dos sons mais graves.

A amplificação já havia nos ensinado que ouvir a música em um volume muito alto era parte inseparável da experiência do rock'n'roll. Por isso o velho bordão "aumenta que isso aí é rock'n'roll" é mais do que um clichê, mas a expressão clara de uma sensorialidade auditiva que demanda intensidade, que vem sendo cultivada já há algumas décadas. A partir dos instrumentos eletrônicos um som potente e muito mais grave aparece.

Diferente das experiências metódico-racionais da elektronische Musik, o novo som sintetizado incorporou-se a estilos de apelo cada vez mais popular. No Brasil, o funk carioca, que teve suas primeiras bases criadas a partir de loops de trechos de músicas da cultura eletrônica - especialmente da banda alemã Kraftwerk, surgida nos anos $70^{11}$-, tem nos graves e na batida repetitiva sua principal arma para criar uma experiência de transe extático. $\mathrm{O}$ paredão de imensos alto-falantes, presente nos bailes funk, reproduzindo o que

\footnotetext{
${ }^{11}$ Cf. a música Planet Rock do Afrika Bambaataa, produzida a partir de um loop da batida de Trans-Europe Express, do Kraftwerk.
} 
convencionamos chamar de "batidão", tem uma função catártica e de envolvimento para os seus frequentadores.

Mesmo em gêneros que não necessariamente demandariam uma presença maior de sons graves podemos perceber um avanço desse tipo de sonoridade. Talvez pelo desejo de se manterem atuais, sensíveis a um padrão de sensorialidade auditiva que se impõe demandando, de modo contínuo e crescente, sons mais intensos, os registros sonoros e audiovisuais como os $c d s$ e $d v d s$, bem como os shows de artistas de MPB, apresentam um corpo de sons graves bem mais evidentes, como nunca antes escutado. Isso pode ser atestado por qualquer produtor musical com algum tempo de experiência profissional e que ainda esteja atuando no mercado fonográfico.

Um outro acontecimento interessante que permite a percepção das novas audibilidades é o aparecimento do movimento noise. Tradução literal de "ruído" para o inglês, o noise se inscreve na história da música tendo suas raízes em propostas tais como a de Russolo, como citamos, que reivindicam uma extensão da experiência da escuta musical para limites ou margens além do que classicamente se considerava como universo musical. Nos dias atuais o noise pode ser pensado como herdeiro direto de outros gêneros experimentais, como o industrial, que trabalham com elementos sonoros extremos, seja em termos de volume, seja em termos de timbres e massa sonora. As performances de noise, como as de um artista como Zbigniev Karkowski, por exemplo, parecem reeditar todo o material sonoro que se quer afastado dos ouvidos, considerado como poluentes auditivos. "Meu interesse é retomar, remexer, recriar e, por fim, reapresentar para um grupo de garotos insanos tudo que possa ser considerado lixo sonoro de uma grande cidade" ${ }^{\prime 2}$.

A força, ou perturbação do noise, está exatamente na dificuldade de se ficar indiferente às suas provocações sonoras. $O$ conjunto sônico que se apresenta nas performances para grupos de aficionados pelo gênero visa comumente explorar explícita e radicalmente as dimensões táteis do som, implicando muitas vezes a construção de espessas camadas sonoras estridentes que vão se metamorfoseando a partir de repetições longas e continuadas, nas quais ritmos e timbres são percebidos como alterados à medida que a escuta se torna saturada pelo próprio excesso sonoro. O que fica após uma dessas apresentações não é uma ou duas melodias para se cantarolar quando se volta para casa, mas a sensação de que

\footnotetext{
${ }^{12}$ Em diálogo com um dos autores (Vinicius A. Pereira), em novembro de 2007, quando Karkowski esteve no Rio de Janeiro para uma série de performances e debates sobre o noise e a cultura digital trash, como convidado do PAN MEDIA LAB ESPM.
} 
todo o corpo está exausto, alterado, impactado pelos bombardeios táteis-sonoros das peças noise.

Por fim, exploremos um pouco as audibilidades que comparecem com os games. A tese básica que defendemos quando analisamos os games e, mais especificamente, seus principais consoles, foi a de que estaríamos diante de um novo estágio das linguagens audiovisuais, com a entrada explícita do tato como sentido requerido para a efetivação da experiência midiática (PEREIRA, 2008).

As audibilidades típicas dos games, especialmente aqueles que se apresentam em jogos de primeira pessoa (com câmera subjetiva, conduzida pelo próprio movimento do personagem que representa o jogador), guardam um paralelo com as visualidades requeridas para estes mesmos jogos. Buscam explorar um ambiente em três dimensões, simulando a exploração de um ambiente físico real. Nessas situações, a sonoridade que permite um deslocamento mais orientado é aquela que possibilita uma experiência de reconhecimento de movimentos, distâncias, massas, velocidades de todas as coisas que compõem o campo explorado. Ou seja, uma sonoridade estereofônica (poderíamos dizer mesmo polifônica).

A audibilidade requerida pelos games se parece muito com aquelas que propunham uma experiência imersiva, seja no cinema, seja nos home theaters. Assim, mais uma vez, veremos as sensorialidades que demandam sons intensos comparecerem, como modo de garantirem essa imersão e, deste modo, uma simulação mais eficaz. Ainda, se consideramos que boa parte dos games se dá como reproduções de campos de batalha e jogos de tiros, timbres e intensidades intensas e graves destacar-se-ão de quaisquer outros sons. Ou seja, podemos dizer que as práticas dos games, de uma maneira geral, garantem a demanda por uma sensorialidade auditiva contemporânea que saiba lidar bem com sons extremos, como os sons graves.

O aumento da complexidade dos games parece revelar uma cultura na qual suas práticas de entretenimento e de comunicação são voltadas, cada vez mais, para a hiperestimulação dos sentidos. Sob certa perspectiva a guerra dos consoles [dos games] parece ser a metáfora de uma cultura que visa a preparar-nos sensorialmente para uma nova realidade, ainda em gestação, que traria como marcas uma alta performance das percepções visuais e auditivas e de ações finas táteis, cinestésicas e proprioceptivas. (PEREIRA, 2008: 11-12)

\section{Considerações finais}

Hans Gumbrecht (2004), ao falar de uma "cultura da presença", abre uma perspectiva interessante para pensarmos os processos de produção de significados das experiências que 
não recorrem, necessariamente, à interpretação. Ele propõe, então, um processo de significação e revelação atrelado à ideia de "epifania". Essa espécie de revelação do mundo é comum a vários tipos de manifestações religiosas como os rituais afro-brasileiros ou rituais católicos como a eucaristia. Nestes episódios o corpo é parte inseparável do processo de "estar-no-mundo" (ideia que Gumbrecht toma emprestada de Heidegger), e suas afetações são parte fundamental de todo conhecimento produzido. Gumbrecht enfatiza, assim, as diferenças e possíveis continuidades entre dois modos de apreensão de significados das coisas no mundo: o hermenêutico e o presencial. Enquanto aquele exige sempre a figura de um decodificador, intérprete por excelência que se personifica em personagens tal como o do exegeta, por exemplo, os processos de produção de significados presenciais são marcados fundamentalmente pelas respostas que cada um, através dos seus próprios corpos, vivências e memórias, apresenta frente a acontecimentos fundamentalmente físicos - música, danças, falas ritmadas, movimentos constantes, luzes, etc. - associados às epifanias.

No presente trabalho, um dos nossos pressupostos é o de que os grandes sons (os graves, os sons potentes e intensos) são uma forma bastante eficaz de mobilizar os corpos nos processos de comunicação contemporâneos mediados tecnologicamente. Curioso como o grande órgão, de que falamos no início do trabalho, tenha sua história estreitamente ligada aos ritos religiosos. Próximos à perspectiva epifânica, proposta por Gumbrecht, podemos arriscar que, ao tocar os corpos, ao fazê-los vibrar, os sons potentes os colocam em uma espécie de perturbação sensorial - que no caso dos propósitos do grande órgão evoca um acontecimento extraordinário, uma experiência de quase transcendência, experiência que tenta traduzir a própria presença divina.

Se pudermos explorar algumas manifestações da cultura sônica contemporânea a partir das ideias propostas por Gumbrecht, poderíamos arriscar que vivemos uma intensificação da cultura da presença. De uma maneira geral, parece que em quase todas as esferas os processos de partilha de significações contam menos com processos de interpretações e mais com experiências.

Em quase todas as esferas das práticas midiáticas contemporâneas parece que os processos de comunicação se tornam menos verbais e simbólicos e mais corpóreos, menos cerebrais e mais sensoriais, menos racionais e mais imaginários, menos sérios e mais lúdicos - talvez seja por isso que muitos leem tais acontecimentos como a nova barbárie.

Poderíamos pensar de outro modo, afirmando que a cultura contemporânea se expressa nas práticas cotidianas midiáticas através, fundamentalmente, da linguagem do 
entretenimento e que, dentro desta linguagem, o contato físico e as experiências sensoriais são decisivos como forma efetiva de envolvimento.

Há, ainda, uma outra perspectiva que podemos considerar: a de que em um mundo hiperestimulado, onde as práticas de comunicação mediadas tecnologicamente estão saturadas de mensagens - expressões que venham em registros monossensoriais (texto, imagens ou áudio) ou em registros bissensoriais, como as linguagens audiovisuais (TV e cinema) -, elas já não chamem tanta atenção, demandando mais sentidos. A partir da emergência da cultura dos games o tato entraria como o sentido extra que intensifica as experiências audiovisuais de até então. Em parte esta perspectiva retoma a ideia do velho McLuhan, quando apostava que o incremento contínuo da comunicação mediada eletronicamente traria de volta o espaço acústico como o espaço, não da audição, mas de todos os sentidos (MCLUHAN, 1964).

Assim, a cultura sônica contemporânea, na sua demanda crescente por sons mais graves, pode ser a manifestação da retomada do espaço acústico. Os sons graves podem traduzir, assim, uma procura por modos e práticas de comunicação que já não cabem exclusivamente dentro de um modelo mono ou bissensorial, como eram típicos das mídias massivas (impressos, TV, rádios, cinema, etc.), aproximando-se muito mais de práticas multissensoriais e performáticas como parecem propor as práticas dos games e dos G.A.M.E.S.2.O. Ser capaz de considerar e explorar, através de questionamentos e encaminhamentos argumentativos, esta nova cultura midiática multissensorial é o objetivo básico dos estudos que procuramos traduzir com o presente artigo.

\section{Referências}

BENJAMIN, Walter. Obras escolhidas: magia e técnica, arte e política. São Paulo: Brasiliense, 1994.

DEWEY, John. Experience and nature. London: George Allen \& Unwin Ltd., Inc, 1929.

GUMBRECHT, Hans Ulrich. O campo não-hermenêutico \& Adeus à interpretação. Rio de Janeiro: UERJ/IL, 1995.

. Production of presence: what meaning cannot convey. Stanford: Stanford University Press, 2004.

KENNEDY, Michael (Ed.). The Oxford dictionary of music. Oxford: Oxford University Press, 2002. 
McLUHAN, Marshall . Understanding media: the extensions of man. New York: The New American Library, 1964.

PEREIRA, Vinícius Andrade. "G.A.M.E.S. 2.0 - Gêneros e gramáticas de arranjos e ambientes midiáticos mediadores de experiências de entretenimento, sociabilidades e sensorialidades". In: Anais do XVII Encontro da Compós, 2008, São Paulo. São Paulo: UNIP, 2008. Disponível em: 〈http://www.compos.org.br/data/biblioteca_294.pdf >.

"Marshall McLuhan, o conceito de determinismo tecnológico e os estudos dos meios de comunicação contemporâneos." In: Razón y Palabra. V. 52, 2006a , p. 52. Disponível em: 〈http://www.unirevista.unisinos.br/_pdf/UNIrev_VAndrade.PDF>.

- "Reflexões sobre as materialidades dos meios: embodiment, afetividade e sensorialidade nas dinâmicas de comunicação das novas mídias". In: Revista Fronteiras: Estudos Midiáticos. Vol. 8, $\mathrm{n}^{\circ}$ 3. São Leopoldo: Unisinos, set-dez, 2006b, p. 93-101. Disponível em: <http://www.unisinos.br/publicacoes_cientificas/images/stories/pdfs_filosofia/vol8n2/art02_p ereira.pdf $>$.

RUSSOLO, Luigi. L'arte dei rumori. Milano: Tip. Taveccia, 1916.

SCHAEFFER, Pierre. Traité des objets musicaux. Paris: Éditions du Seuil, 1966.

SCHAFER, R. Murray. A afinação do mundo: uma exploração pioneira pela história passada e pelo atual estado do mais negligenciado aspecto do nosso ambiente: a paisagem sonora. São Paulo: Unesp, 2001.

SERGI, Gianluca. The Dolby era: film sound in contemporary Hollywood. Manchester; New York: Manchester University Press, 2004.

SIMMEL, Georg. "A metrópole a a vida mental." In: VELHO, Otávio G. O fenômeno urbano. Rio de Janeiro: Ed. Guanabara, 1987, p. 11-25.

SINGER, Ben. "Modernidade, Hiperestímulo e o Início do Sensacionalismo Popular." In CHARNEY, Leo; SCHWARTZ, Vanessa R. (Org.). O cinema e a invenção da vida moderna. São Paulo: Cosac \& Naify, 2004, p. 95-123.

TAYLOR, Timothy D. Strange sounds: music, technology \& culture. New York: Routledge, 2001. 